\title{
Odor recognition memory is not independently impaired in Parkinson's disease
}

\author{
Sanne Boesveldt $\cdot$ R. J. O. de Muinck Keizer • \\ E. Ch. Wolters $\cdot$ H. W. Berendse
}

Received: 14 August 2008/Accepted: 17 March 2009/Published online: 2 April 2009

(C) Springer-Verlag 2009

\begin{abstract}
The results of previous studies in small groups of Parkinson's disease (PD) patients are inconclusive with regard to the presence of an odor recognition memory impairment in PD. The aim of the present study was to investigate odor recognition memory in PD in a larger group of patients. Odor recognition memory and detection thresholds were assessed using components of the "Sniffin' Sticks" test battery in 55 non-demented PD patients (Hoehn and Yahr stages I-III) and 50 control subjects of comparable age and sex. PD patients performed slightly but significantly worse than control subjects on the odor recognition memory task. After correction for odor detection scores, however, the difference in odor recognition memory performance between PD patients and controls was no longer statistically significant. These data indicate that odor recognition memory is not independently impaired in PD patients.
\end{abstract}

Keywords Olfaction · Parkinson's disease ·

Odor recognition memory $\cdot$ Detection

\section{Introduction}

Olfactory deficits in Parkinson's disease (PD) were first empirically documented in 1975 by Ansari and Johnson.

S. Boesveldt $\cdot$ R. J. O. de Muinck Keizer

E. Ch. Wolters - H. W. Berendse

Department of Neurology, VU University Medical Center,

Amsterdam, The Netherlands

S. Boesveldt $(\bowtie)$

Monell Chemical Senses Center, 3500 Market Street,

Philadelphia, PA 19104, USA

e-mail: sboesveldt@monell.org
Over the ensuing years, it has become clear that most PD patients have olfactory disturbances that are not restricted to a single functional measure but include impairments of odor detection, discrimination and identification (for review see Doty 1991). Clinical deficits in the sense of smell may even precede the development of overt motor symptoms (Haehner et al. 2007; Ponsen et al. 2004).

Few studies have addressed odor recognition memory performance in PD patients. The results of these studies are inconclusive. A review paper based upon three small studies concluded that odor recognition memory is impaired in PD patients (Mesholam et al. 1998), whereas a separate study suggested that odor recognition memory may be intact in PD (Lehrner et al. 1997).

Reduced olfactory acuity may, at least theoretically, affect performance on other olfactory tasks and thus lead to an underestimation of the actual performance on the olfactory task in question. It has been argued that olfactory detection thresholds should therefore always be assessed in addition to the specific olfactory measure under consideration and used in appropriate statistical analyses to correct for impairments in odor detection (Martzke et al. 1997). The aim of the present study was to investigate odor recognition memory in a larger group of PD patients.

\section{Methods}

Subjects

This study was performed in 55 control subjects and $63 \mathrm{PD}$ patients. Eight subjects (four control subjects and four PD patients) had a score below 25 on the Mini Mental State Examination (Folstein et al. 1975) or a score below 27 on the CAMbridge COGnitive examination (Roth et al. 1986) 
on the day of olfactory testing, and were therefore excluded. In addition, five subjects (one control subject and four PD patients) did not complete both olfactory tasks and were excluded. Fifty-five non-demented PD patients (31 males and 24 females; mean age 62.0 years, range 50 73 years, Hoehn and Yahr (H\&Y) stages I-III, disease duration 0-19 years), and 50 control subjects (27 males and 23 females; mean age 59.5 years, range 49-78 years) remained in the study. All PD patients were recruited from the outpatient clinic for movement disorders of the Department of Neurology of the VU University Medical Center (VUMC) or via advertisements on Parkinson's disease-related websites on the internet. Parkinson's disease was diagnosed according to the United Kingdom Parkinson's Disease Society Brain Bank criteria. Four patients were drug-naive. Of the remaining PD patients, three patients were treated with levodopa monotherapy, five patients were on dopamine-agonist monotherapy, 18 patients were treated with a combination of both levodopa and a dopamine agonist, and 25 patients used levodopa, a dopamine agonist, as well as other medication, including monoamine oxidase B (MAO-B) inhibitors, catechol-Omethyltransferase (COMT) inhibitors, parasympathicolytica and beta-blockers. Medicated patients were tested in the 'ON' state, and all patients were rated for disease stage by means of the modified H\&Y scale (Jankovic et al. 1990), and for motor symptom severity by the Unified Parkinson's Disease Rating Scale III (UPDRS-III). All control subjects were volunteers recruited among hospital employees and partners of patients, reported normal subjective olfactory function and had no history of major olfactory or neurological disorders. All subjects provided written informed consent. The study was approved by the Medical Ethics Committee of the VUMC.

\section{Olfactory testing}

Odor recognition memory and odor detection threshold were assessed using components of the "Sniffin' Sticks" test battery (Burghart, Wedel, Germany) (Hummel et al. 1997).

For the odor recognition memory task, we used the odorants of the extended identification part of the "Sniffin' Sticks" (Reden et al. 2006). Subjects were presented with eight target odorants, with an interval of approximately $10 \mathrm{~s}$ between odorants, and were asked to memorize them. No verbal descriptions were provided. After repeating the instructions on the task, 16 odors (eight target odors, eight distracters; Table 1) were presented and the subject was asked whether the odor had been smelled before. A fixed presentation order of the target and distracter odors was randomly selected at the onset of the study and used for all participants. Odor recognition memory scores were
Table 1 Target and distracter odors used in the odor recognition memory task

\begin{tabular}{ll}
\hline Target odors & Distracter odors \\
\hline Lilac & Pear \\
Grass & Coke \\
Peach & Grapefruit \\
Raspberry & Ginger \\
Mushroom & Coconut \\
Onion & Melon \\
Honey & Smoked meat \\
Lavender & Chocolate \\
\hline
\end{tabular}

calculated as "proportion correct" measure: correctly recognized target odors $(0-8)$ plus correctly recognized distracter odors $(0-8)$, divided by the total number of targets and distracters (16).

Odor detection threshold was assessed using a singlestaircase, three-alternative forced-choice procedure, with a $1: 2$ dilution series of 16 stages. Subjects had to identify the odor-containing pen when presented with three pens, two containing the solvent and one the odorant (score 0-16). Subjects who were unable to correctly identify even the highest concentration of the odor-containing pens received a score of 0 .

Subjects were blindfolded during the two tests to prevent visual identification of the sticks. Olfactory tests were administered birhinally in a quiet, well-ventilated room to avoid any background smell interfering with the test odors.

\section{Data analysis}

Since olfactory function is generally considered to be ageand sex-dependent we used these terms as covariates in our analyses (Doty et al. 1984, 1985).

Odor recognition memory scores ('proportion correct') were analyzed by means of an analysis of variance (ANOVA), with 'group' as factor, and 'age', 'sex', and 'detection score' as covariates, using SPSS 15.0 for Windows (Chicago, IL, USA).

To explore sex differences in odor recognition memory performance, data were analyzed by means of an ANOVA, with 'sex' as factor, and 'group', 'age', and 'detection score' as covariates.

To investigate a possible relation between odor recognition memory performance and disease duration or severity, data of the PD patients were analyzed by means of an ANOVA with 'disease duration' (in years, based on first symptoms perceived by the patient), 'disease stage' (modified H\&Y scale), 'motor symptom severity' (as measured by the UPDRS III), 'sex', and 'age', as determinants. 


\section{Results}

The mean number of correctly recognized target odors $( \pm$ SEM) was $6.3 \pm 0.19$ for control subjects, and $5.2 \pm 0.23$ for PD patients. The mean number of correct rejections $( \pm$ SEM) was $4.4 \pm 0.25$ for control subjects, and $3.6 \pm 0.22$ for PD patients. Total odor recognition memory score ("proportion correct"; \pm SEM) was $0.67 \pm 0.019$ for control subjects, and $0.55 \pm 0.018$ for PD patients (Fig. 1a). PD patients scored significantly different from 'chance level' (proportion correct $=0.5$; one-sample $t$ test, $p=0.006)$. Mean odor detection threshold score $( \pm$ SEM) was $7.9 \pm 0.41$ for control subjects, and $2.4 \pm 0.36$ for PD patients.

Odor recognition memory scores were significantly lower in PD patients than in control subjects $(F[1,101]=$ 15.594, $p<0.001)$, when corrected only for age and sex. When odor recognition memory scores were also adjusted for odor detection threshold scores, there was no significant difference between PD patients and control subjects $(F[1,100]=0.873, p=0.352$; Fig. $1 b)$.

After exclusion of subjects that were unable to detect the odorant at the highest concentration in the threshold task ( $n=14$, all PD patients), the results of the analysis did not change: odor recognition memory scores were significantly lower in PD patients than in control subjects $(F[1,87]=$ $10.433, p=0.002$ ), when corrected only for age and sex. When odor recognition memory scores were also adjusted for odor detection threshold scores, there was no significant difference between PD patients and control subjects $(F[1,86]=0.848, p=0.360)$.

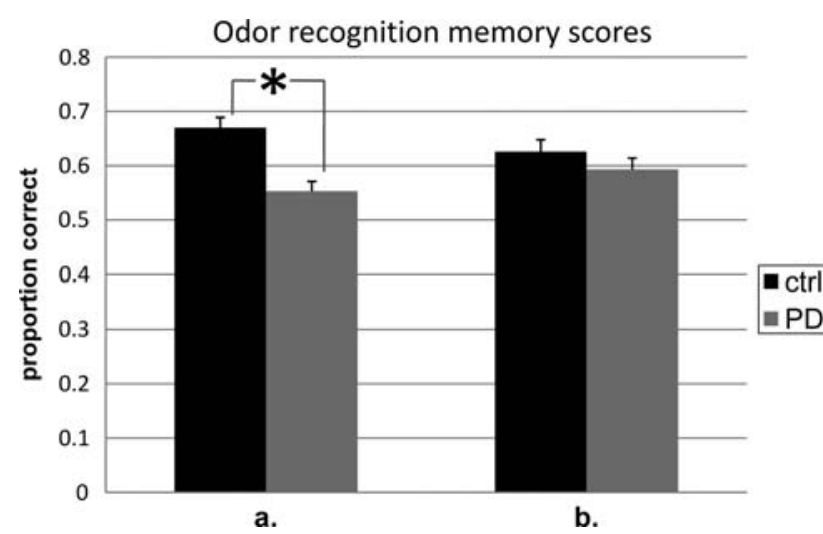

Fig. 1 Odor recognition memory scores. a Mean odor recognition memory scores ('proportion correct') and standard errors of the mean, for control subjects and Parkinson's disease patients. * $p$ value $<0.05$, based upon an ANOVA with 'group' as factor. b Mean odor recognition memory scores ('proportion correct') and standard errors of the mean, for control subjects and Parkinson's disease patients, after statistical correction for age, sex and odor detection threshold scores
There was no main effect of sex with respect to odor recognition memory scores $(F \quad[1,100]=0.647$, $p=0.423$ ), when corrected for age and odor detection threshold scores. No relationship was found between disease duration $(F[1,49]=2.627, p=0.111)$, disease stage $(F[1,49]=1.080, p=0.304)$ or motor symptom severity $(F[1,49]=0.890, p=0.350)$ and odor recognition performance, when corrected for age and sex.

\section{Discussion}

The results of the present study demonstrate that PD patients had slightly but significantly lower odor recognition memory scores than control subjects. However, when odor recognition memory scores were corrected for odor detection threshold scores, the difference between PD patients and control subjects lost statistical significance.

Few studies have previously addressed odor recognition memory performance in PD patients, and the results of these studies are inconclusive. In a meta-analysis Mesholam et al. concluded that odor recognition memory was impaired in PD (Mesholam et al. 1998). However, the analysis was based on only three small studies, including a study by Kesslak et al. that lacked statistical significance due to the low number of subjects $(n=4)$ (Kesslak et al. 1988) and a study by Zucco et al. in which no difference had been found between PD patients and control subjects (Zucco et al. 1991). In the third study, an odor recognition paradigm was used that actually did not involve a memory component (Corwin et al. 1985). In contrast, the results of a separate study in PD patients suggested that odor recognition memory is intact (Lehrner et al. 1997). Although our results without correction for odor detection threshold would seem to support the conclusion by Mesholam et al. that there is a slight impairment of odor recognition memory in PD, the present data indicate that this slight impairment is not independent of the deficit in odor detection.

To correct for the influence of olfactory acuity on odor recognition memory performance - a methodological issue that was previously raised (Martzke et al. 1997)—we used a statistical correction for odor detection thresholds. Using this approach, we found no significant difference between PD patients and control subjects on the odor recognition memory task. Although the odors used in the recognition memory task were overall perceptually stronger than the odorant at the highest concentration in the threshold task, some of the PD patients may not have been able to perceive the target odors sufficiently well to memorize and recognize them afterwards. However, even when we excluded patients that were completely anosmic according to their performance on the threshold task, the results remained unchanged. 
Doty et al. have suggested that most olfactory tests measure a common source of variance, and that an impairment in olfactory acuity may also underlie reduced performance on other olfactory tasks in PD (Doty et al. 1994). However, this does not seem to apply to all olfactory measures, since in at least two recent studies odor identification and discrimination deficits were independent from the increase in odor detection threshold (Boesveldt et al. 2009; Tissingh et al. 2001). The current findings suggest that the olfactory impairments in PD, which appear to involve several specific olfactory functions, do not include odor recognition memory.

In Alzheimer's disease (AD), previous studies have reported odor recognition memory to be impaired (Mesholam et al. 1998; Lehrner et al. 1997), even when corrected for odor detection thresholds (Gilbert et al. 2004; Nordin and Murphy 1996; Koss et al. 1987). Therefore, testing of odor recognition memory may prove useful in the differential diagnosis between $\mathrm{PD}$ patients and $\mathrm{AD}$ patients, in particular in the context of early diagnostic procedures. Future studies directly comparing groups of PD and AD patients are necessary to confirm this.

In conclusion, the present data indicate that odor recognition memory is not independently impaired in PD patients.

Acknowledgments This research was funded by the AlkemadeKeuls Foundation and the Dutch Parkinson's Disease Association.

Conflict of interest statement None.

\section{References}

Ansari KA, Johnson A (1975) Olfactory function in patients with Parkinson's disease. J Chronic Dis 28:493-497

Boesveldt S, de Muinck Keizer RJO, ECh Wolters, Berendse HW (2009) Extended testing across, not within, tasks raises diagnostic accuracy of olfactory testing in Parkinson's disease. Mov Disord 24:85-90

Corwin J, Serby M, Conrad P, Rotrosen J (1985) Olfactory recognition deficit in Alzheimer's and Parkinsonian dementias. IRCS J Med Sci 13:260

Doty RL (1991) Olfactory dysfunction in neurodegenerative disorders. In: Getchell TV (ed) Smell and taste in health and disease. Raven Press, New York, pp 735-751

Doty RL, Shaman P, Applebaum SL, Giberson R, Siksorski L, Rosenberg L (1984) Smell identification ability: changes with age. Science 226:1441-1443

Doty RL, Applebaum S, Zusho H, Settle RG (1985) Sex differences in odor identification ability: a cross-cultural analysis. Neuropsychologia 23:667-672
Doty RL, Smith R, McKeown DA, Raj J (1994) Tests of human olfactory function: principal components analysis suggests that most measure a common source of variance. Percept Psychophys 56:701-707

Folstein MF, Folstein SE, McHugh PR (1975) Mini-mental state. A practical method for grading the cognitive state of patients for the clinician. J Psychiatr Res 12:189-198

Gilbert PE, Barr PJ, Murphy C (2004) Differences in olfactory and visual memory in patients with pathologically confirmed Alzheimer's disease and the Lewy body variant of Alzheimer's disease. J Int Neuropsychol Soc 10:835-842

Haehner A, Hummel T, Hummel C, Sommer U, Junghanns S, Reichmann H (2007) Olfactory loss may be a first sign of idiopathic Parkinson's disease. Mov Disord 22:839-842

Hummel T, Sekinger B, Wolf SR, Pauli E, Kobal G (1997) 'Sniffin'Sticks': olfactory performance assessed by the combined testing of odor identification, odor discrimination and olfactory threshold. Chem Senses 22:39-52

Jankovic J, McDermott M, Carter J, Gauthier S, Goetz C, Golbe L, Huber S, Koller W, Olanow C, Shoulson I, Stern M, Tanner C, Weiner W, Parkinson Study Group (1990) Variable expression of Parkinson's disease: a base-line analysis of the DATATOP cohort. Neurology 40:1529-1534

Kesslak JP, Cotman CW, Chui HC, Van den Noort S, Fang H, Pfeffer R, Lynch G (1988) Olfactory tests as possible probes for detecting and monitoring Alzheimer's disease. Neurobiol Aging 9:399-403

Koss E, Weiffenbach JM, Haxby JV, Friedland RP (1987) Olfactory detection and recognition in Alzheimer's disease. Lancet 1:622

Lehrner JP, Brucke T, Dal-Bianco P, Gatterer G, Kryspin-Exner I (1997) Olfactory function in Parkinson's disease and Alzheimer's disease. Chem Senses 22:105-110

Martzke JS, Kopala LC, Good KP (1997) Olfactory dysfunction in neuropsychiatric disorders: review and methodological considerations. Biol Psychiatry 42:721-732

Mesholam RI, Moberg PJ, Mahr RN, Doty RL (1998) Olfaction in neurodegenerative disease: a meta-analysis of olfactory functioning in Alzheimer's and Parkinson's diseases. Arch Neurol 55:84-90

Nordin S, Murphy C (1996) Impaired sensory and cognitive olfactory function in questionable Alzheimer's disease. Neuropsychology 10:113-119

Ponsen MM, Stoffers D, Booij J, van Eck-Smit BLF, ECh Wolters, Berendse HW (2004) Idiopathic hyposmia as a preclinical sign of Parkinson's disease. Ann Neurol 56:173-181

Reden J, Mayer A, Hummel T (2006) An extended version of the "Sniffin' Sticks". Chem Senses 31:A39

Roth M, Tym E, Mountjoy CQ, Huppert FA, Hendrie H, Verma S, Goddard R (1986) CAMDEX. A standardised instrument for the diagnosis of mental disorder in the elderly with special reference to the early detection of dementia. Br J Psychiatry 149:698-709

Tissingh G, Berendse HW, Bergmans P, DeWaard R, Drukarch B, Stoof JC, Wolters EC (2001) Loss of olfaction in de novo and treated Parkinsons's disease: possible implications for early diagnosis. Mov Disord 16:41-46

Zucco GM, Zaglis D, Wambsganss CS (1991) Olfactory deficits in elderly subjects and Parkinson patients. Percept Mot Skills 73:895-898 